\title{
First experience with BAK-free travoprost $0.004 \%$ in topical glaucoma medication
}

This article was published in the following Dove Press journal:

Clinical Ophthalmology

12 December 2011

Number of times this article has been viewed

\section{Ahmed Salah Gado Tamer Ahmed Macky \\ Department of Ophthalmology, Cairo University, Cairo, Egypt}

Correspondence: Ahmed Salah Gado 16 Gilmorton Close, Hillfield, Solihull, West Midlands, UK B9I 3FD Mobile +44 7986130548 Email gado_ophthalmol@hotmail.com
Objectives: Benzalkonium chloride (BAK)-free travoprost $0.004 \%$ (Travatan $Z^{\circledR}$, Alcon Laboratories, Inc, Fort Worth, TX) is a new formulation that was developed with the aim of creating a formulation of travoprost that would maintain the intraocular pressure (IOP)-lowering efficacy and have an improved overall safety profile, particularly improved ocular surface tolerability.

Methods: Thirty newly diagnosed primary open-angle glaucoma (POAG) patients were treated with BAK-free travoprost $0.004 \%$. IOP readings were recorded at baseline before initiating treatment, at 4-6 weeks, and after 12 weeks of starting treatment. In addition, patient demographics, subjective symptoms (ie, burning, foreign-body sensation, itching, and stinging), and objective clinical signs such as conjunctival hyperemia were collected. Subjective symptoms were evaluated using a four-point scale ranging from "no symptoms," "mild symptoms," "moderate symptoms" to "severe symptoms." As for clinical signs, severity of conjunctival hyperemia was evaluated. All other adverse events were collected.

Results: BAK-free travoprost $0.004 \%$ provided an IOP decrease in all patients, with an overall mean of $28.3 \pm 2.1 \mathrm{mmHg}$ at baseline to a mean of $18.7 \pm 1.6 \mathrm{mmHg}$ at $4-6$ weeks, and a mean of $18.4 \pm 1.4 \mathrm{mmHg}$ after 12 weeks. Both subjective symptoms and objective clinical signs were very few after treatment.

Conclusion: The results demonstrate that BAK-free travoprost $0.004 \%$ is an effective, well tolerated, and safe medication in POAG patients.

Keywords: primary open-angle glaucoma, POAG, benzalkonium chloride, Travatan

\section{Introduction}

Glaucoma is the second leading cause of blindness worldwide. Increased intraocular pressure (IOP) is considered to be the most important risk factor and the only one that can be modified. Major outcome studies published in recent years have shown that lowering IOP is beneficial for patients with primary open-angle glaucoma (POAG). ${ }^{1}$ Worldwide, prostaglandins have become a major therapeutic class for medical treatment of glaucoma because of their excellent efficacy and favorable safety profile. ${ }^{2}$ However, many prostaglandin analogs contain preservatives that may be toxic to the eye. The most common preservative in IOP-lowering medications is benzalkonium chloride (BAK), a quaternary ammonium compound that causes bacterial cell death by lysing cytoplasmic membranes. ${ }^{3}$

BAK has demonstrated toxicity against both corneal and conjunctival cells when administered in the range of concentrations present in ophthalmic medications (0.004\%-0.020\%). Moreover, in vitro, animal, and clinical studies have demonstrated that BAK-containing medications are associated with greater toxicity, increased 
Table I Patient demographics

\begin{tabular}{ll}
\hline Patient $(\mathrm{N})$ & 30 (60 eyes) \\
Mean age & $58.9 \pm 3.4$ years \\
Gender & \\
Male & $(\mathrm{N}=14 ; 46.7 \%)$ \\
Female & $(\mathrm{N}=16 ; 53.3 \%)$ \\
\hline
\end{tabular}

Note: Characteristics of the patient population included in the study.

ocular surface damage, and decreased tolerability compared with BAK-free preparations. ${ }^{4}$ Instead of using BAK as a preservative, BAK-free travoprost $0.004 \%$ (Travatan $Z^{\circledR}$, Alcon Laboratories, Inc, Fort Worth, TX) contains the alternative preservative system SofZia ${ }^{\mathrm{TM}}$ (Alcon Laboratories, Inc), containing borate, zinc, and sorbitol. ${ }^{5}$

Although limited research has been published on SofZia, a relatively new preservative, available studies report no significant difference in ocular toxicity between travoprost BAK-free and preservative-free artificial tears. ${ }^{6}$ Both in-vitro and in-vivo studies directly comparing travoprost BAK-free with latanoprost, show that travoprost BAK-free is less toxic to the cornea and conjunctiva. ${ }^{7}$ In addition, a transition study by Horsley and $\mathrm{Kahook}^{8}$ also reported that patients with reduced tear breakup time who transitioned to travoprost BAK-free monotherapy after at least 1 year of latanoprost monotherapy had decreased corneal staining, longer tear breakup time, and fewer ocular surface disease symptoms, while maintaining equivalent IOP-lowering efficacy. Therefore, the goal of the current study was to examine the efficacy, safety, and tolerability of travoprost $0.004 \%$ BAKfree in patients with POAG.

\section{Patients and methods}

In this open-label study, 30 newly diagnosed patients with POAG were followed up for 12 weeks after starting them on travoprost $0.004 \%$ BAK-free once daily. The initiation of this treatment modality was based on the decision of the physician only. Consent forms were not required since the drug was already approved for ophthalmic use; however, verbal consent for commencing the treatment was obtained from the patients before starting them on treatment.

\section{Exclusion criteria}

Patients with previous history of corneal refractive surgery, wearing contact lenses, or having clinically significant ocular surface diseases at baseline such as blepharitis, ocular seasonal allergy, or dry eye were excluded from the study. Other exclusion criteria included patients chronically using ocular medications other than the study medication such as artificial tears or antihistamines, and patients who were pregnant or nursing or who could become pregnant during the study were also excluded. Patients with IOP higher than $30 \mathrm{mmHg}$ at baseline visit or those who had undergone glaucoma filtrating surgeries were also excluded.

Using a standardized data collection form, medical data were collected for the patients' that required an initiation of an IOP-lowering therapy to achieve IOP control. Others were kept anonymous. Clinical examination data like IOP readings were recorded. IOP measurements were made using Goldman applanation tonometry for each eye at baseline (prior to starting treatment), at 4-6 weeks, and 12 weeks after starting treatment with travoprost $0.004 \%$ BAK-free eye drops. All measurements were recorded at 4:00 PM to avoid any diurnal variations of the IOP. All adverse events were recorded.

\section{Statistical methods}

Data were statistically described in terms of mean \pm standard deviation, frequencies (number of cases), and percentages when appropriate. Data distribution was tested using Kolmogorov Smirnov test. Since numerical data were not violating normal assumption, comparison between the study groups was done using Student $t$-test for independent samples. Exact test was used instead when the expected frequency was less than 5. $P$-values less than 0.05 were

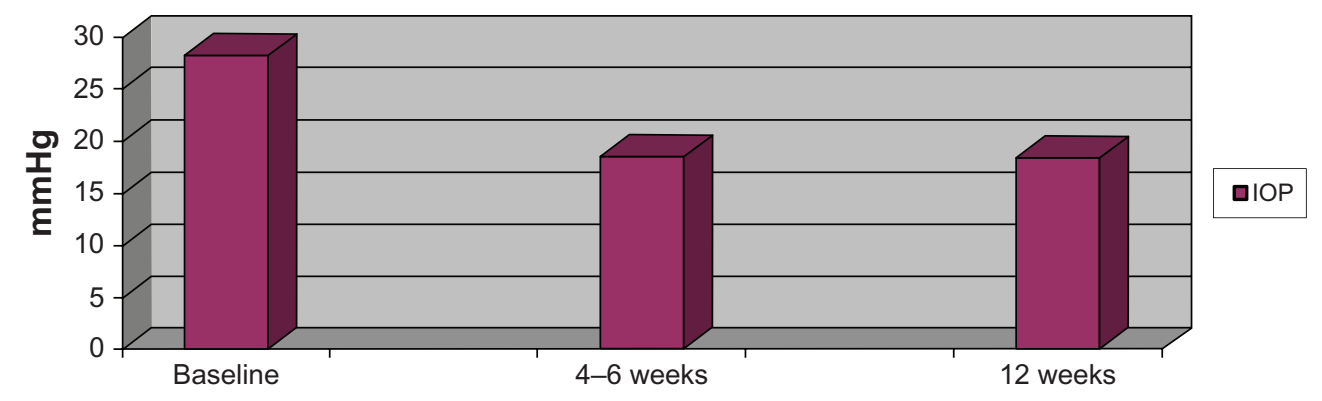

Figure I Mean IOP at baseline, 4-6 weeks, and 12 weeks. Abbreviation: IOP, intraocular pressure. 


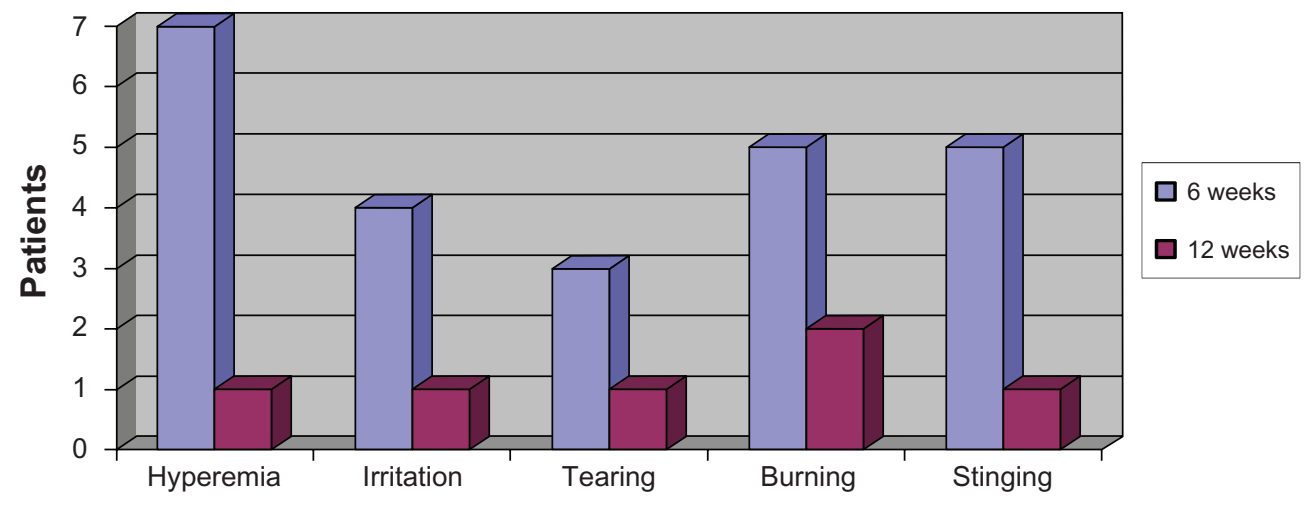

Figure 2 Frequency and severity of ocular symptoms and hyperemia at 6 and 12 weeks.

considered statistically significant. All statistical calculations were done using SPSS Statistics (SPSS Inc, Chicago, IL) software, version 15 for Microsoft Windows.

\section{Results}

\section{Patient population}

Thirty patients ( 60 eyes) were included in the study (Table 1 ). The majority of the patients $(\mathrm{N}=16 ; 53.3 \%)$ were females. All patients were diagnosed with POAG upon commencing therapy.

\section{Effect on IOP}

Overall, mean IOP was $28.3 \pm 2.1 \mathrm{mmHg}$ at baseline. Four to six weeks after treatment, overall mean IOP was reduced to a mean of $18.7 \pm 1.6 \mathrm{mmHg}$ and after 12 weeks to a mean of $18.4 \pm 1.4 \mathrm{mmHg}$. At both 4-6 weeks and 12 weeks, overall, treated IOP values were significantly lower than baseline values ( $P$-values $=0.023$ and 0.018 respectively) . The IOP reduction is equivalent to $33.9 \%$ and $34.9 \%$ from treated baseline, respectively (Figure 1).

\section{Subjective signs and clinical symptoms}

All patients $(\mathrm{N}=30,100 \%)$ indicated they tolerated travoprost $0.004 \%$ BAK-free quite well. None of them discontinued their eye drops during the 3-month follow-up period, and all responded to their treatment (IOP reduction noted in $100 \%$ of patients). Subjective symptoms like irritation, tearing, burning, and stinging were few by the end of the study period (12 weeks of treatment).

The most important clinical sign was hyperemia. It was reduced over the 3-month treatment period significantly from seven patients ( $23.3 \%$ at 6 weeks) to only one patient (3.3\%) having mild to moderate degree of hyperemia at 12 weeks (Figure 2). Systemic tolerability was also noted, and most patients did not report any complications because of that.

\section{Discussion}

The results of this open-label study demonstrate that travoprost $0.004 \%$ BAK-free can achieve good IOP control. Travoprost $0.004 \%$ BAK-free lowered mean IOP significantly compared with the mean pretreatment IOP levels from $28.3 \pm 2.1 \mathrm{mmHg}$ at baseline to $18.7 \pm 1.6 \mathrm{mmHg}(33.9 \%)$ at 4-6 weeks and $18.4 \pm 1.4 \mathrm{mmHg}(34.9 \%)$ at final visit (12 weeks). A similar effect was found by Uusitalo et al in patients after a washout period for their prior medications. ${ }^{9}$ A large body of evidence from experimental and clinical studies exists, showing that the long-term use of topical drugs containing BAK as a preservative may induce changes of the ocular surface, tear film instability, epithelial apoptosis, conjunctival inflammation, and loss of goblet cells. ${ }^{6}$

After continuing to use travoprost $0.004 \%$ BAK-free, subjective symptoms and clinical signs as well as local tolerability improved in most patients, and overall patient satisfaction with their glaucoma treatment increased. The authors of this paper assumed that the further reduction in the IOP and the improvement in the subjective symptoms and hyperemia at the end of the study period ( 12 weeks) compared with the 6 weeks evaluation visit was due to better compliance of the patients to their treatment.

Consistent with previous reports, ${ }^{10}$ the results of this present study suggest that patients with irritation of the ocular surface, ie, subjective symptoms like burning, stinging, foreign body sensation, dry eye, and clinical changes of the eye surface (ie, hyperemia) may benefit from a change of medication to the travoprost $0.004 \%$ BAK-free as it has proved a high level of local tolerability and a marked decrease in subjective symptoms and clinical signs during the study period (12 weeks).

Gandolfi et $\mathrm{al}^{11}$ reported in their study that the intraocular pressure IOP-lowering effect of travoprost $0.004 \%$ BAK-free is noninferior to that of travoprost $0.004 \%$ preserved with 
BAK (travoprost BAK) in patients with ocular hypertension or open-angle glaucoma. Mean IOP reductions from baseline ranged from 7.6 to $8.7 \mathrm{mmHg}$ in the travoprost $\mathrm{BAK}$-free group and from 7.7 to $9.2 \mathrm{mmHg}$ in the travoprost BAK group. The safety profile of travoprost BAK-free was similar to that of travoprost BAK.

This study is limited by its open-label design. The observed IOP reduction might be ascribed to the improvement of subjective symptoms and clinical signs and thus a better compliance. The results identify several factors associated with the use of travoprost $0.004 \%$ BAK-free, such as an improvement in subjective symptoms and clinical signs over the study period. The study data further suggest that a change of a monotherapy treatment regimen to travoprost $0.004 \%$ BAK-free is worthwhile for patients who are responding inadequately to another monotherapy treatment regimen if it is attributed to poor patients' compliance because of their local intolerability.

A detailed analysis of the effects of travoprost $0.004 \%$ BAK-free used in concomitant therapy or as add-on to an existing medical treatment was not done in this study due to the limited number of patients. Further studies with higher numbers of patients are necessary to determine what aspects of travoprost $0.004 \%$ BAK-free account for the observed treatment effects.

\section{Conclusion}

In this study, travoprost $0.004 \%$ BAK-free was effective, well tolerated, and associated with few adverse effects in POAG patients. A change of medical therapy to travoprost $0.004 \%$ BAK-free may be beneficial, especially for patients with subjective ocular symptoms and/or clinical signs, patients with sensitive or dry eyes, and also patients who are not responding adequately to other monotherapy treatment regimens since the new formulation (travoprost $0.004 \%$
BAK-free) demonstrated a high degree of local tolerability with marked decrease in subjective symptoms and clinical signs over the study period (3 months).

\section{Disclosure}

The authors report no conflicts of interest in this work.

\section{References}

1. Heijl A, Leske MC, Bengtsson B, et al. Reduction of intraocular pressure and glaucoma progression: results from the Early Manifest Glaucoma Trial. Arch Ophthalmol. 2002;120:1268-1279.

2. Bean GW, Camras CB. Commercially available prostaglandin analogs for the reduction of intraocular pressure: similarities and differences. Surv Ophthalmol. 2008;53(Suppl 1):S69-S84.

3. Noecker R. Effects of common ophthalmic preservatives on ocular health. Adv Ther. 2001;18(5):205-215.

4. Yee RW, Norcom EG, Zhao XC. Comparison of the relative toxicity of travoprost $0.004 \%$ without benzalkonium chloride and latanoprost $0.005 \%$ in an immortalized human cornea epithelial cell culture system. Adv Ther. 2006;23(4):511-519.

5. Kahook MY, Noecker RJ. Comparison of corneal and conjunctival changes after dosing of travoprost preserved with sofZia, latanoprost with $0.02 \%$ benzalkonium chloride, and preservative-free artificial tears. Cornea. 2008;27(3):339-343.

6. Kahook MY, Noecker R. Quantitative analysis of conjunctival goblet cells after chronic application of topical drops. Adv Ther. 2008;25(8): 743-751.

7. Baudouin C, Riancho L, Warnet JM, Brignole F. In vitro studies of antiglaucomatous prostaglandin analogues: travoprost with and without benzalkonium chloride and preserved latanoprost. Invest Ophthalmol Vis Sci. 2007;48(9):4123-4128.

8. Horsley MB, Kahook MY. Effects of prostaglandin analog therapy on the ocular surface of glaucoma patients. Clin Ophthalmol. 2009;3: 291-295.

9. Uusitalo H, Pillunat LE, Ropo A, et al. Efficacy and safety of tafluprost $0.0015 \%$ versus latanoprost $0.005 \%$ eye drops in open-angle glaucoma and ocular hypertension: 24 month results of a randomized, doublemasked Phase III study. Acta Ophthalmol. 2010;88:12-19.

10. Uusitalo H, Chen E, Pfeiffer N, et al. Switching from a preserved to a preservative-free prostaglandin preparation in topical glaucoma medication. Acta Ophthalmol. 2010;88:329-336.

11. Gandolfi S, Paredes T, Goldberg I, et al. Comparison of a travoprost BAK-free formulation preserved with polyquaternium-1 with BAKpreserved travoprost in ocular hypertension or open-angle glaucoma. Eur J Ophthalmol. Epub June 24, 2011.
Clinical Ophthalmology

\section{Publish your work in this journal}

Clinical Ophthalmology is an international, peer-reviewed journal covering all subspecialties within ophthalmology. Key topics include: Optometry; Visual science; Pharmacology and drug therapy in eye diseases; Basic Sciences; Primary and Secondary eye care; Patient Safety and Quality of Care Improvements. This journal is indexed on Submit your manuscript here: http://www.dovepress.com/clinical-ophthalmology-journal

\section{Dovepress}

PubMed Central and CAS, and is the official journal of The Society of Clinical Ophthalmology (SCO). The manuscript management system is completely online and includes a very quick and fair peer-review system, which is all easy to use. Visit http://www.dovepress.com/ testimonials.php to read real quotes from published authors. 